\title{
Tailored Thermal Expansion Alloys
}

\author{
J.A. Monroe, D. Gehring, I. Karaman*, R. Arroyave \\ Texas A\&M University, Department of Materials Science and Engineering, College Station, Texas, USA \\ D.W. Brown, B. Clausen \\ MST-8, Los Alamos National Laboratory, Los Alamos, New Mexico, USA \\ *: Corresponding author: ikaraman@tamu.edu
}

\begin{abstract}
Current approaches to tailoring the thermal expansion coefficient of materials or finding materials with negative thermal expansion rely on careful manipulation of either the material's composition and/or the complex fabrication of composites. Here, by contrast, we report a new principle that enables the precise control of macroscopic thermal expansion response of bulk materials via crystallographic texture manipulation and by taking advantage of anisotropic Coefficients of Thermal Expansion (CTE) in a large class of martensitically transforming materials. Through simple thermo-mechanical processing, it is possible to tailor the thermal expansion response of a single material —without manipulating its composition - over a wide range of positive and negative values. We demonstrate this principle by gradually tuning the macroscopic CTE in a model NiTiPd alloy between a positive $(+14.90 \times 10-6$ ? -1$)$ and a negative $(-3.06 \times 10-6$ a -1$)$ value, simply by incrementally increasing tensile plastic deformation in the martensite phase. This surprising response is linked to the large positive, $+51.33 \times 10-6 \mathrm{~K}-1$, and negative, $-34.51 \times 10-6 \mathrm{~K}-1$, CTE anisotropy, at the lattice level, along the different crystal directions in martensite. Similar CTE anisotropy is also shown experimentally in CoNiGa and TiNb alloys. In a model TiNb alloy, giant macroscopic CTEs of $+181 \times 10-6$ a -1 and -142×10-6? -1 are measured. A connection between the CTE anisotropy and the martensitic transformation in these and other materials systems such as $\mathrm{NiTi}$, pure uranium, and $\mathrm{PbTiO}_{3}$ is later made. It is shown that negative or positive thermal expansion crystallographic directions are connected to the crystallographic relationship between the austenite and martensite lattices, and can easily be predicted using the lattice parameters of austenite and martensite phases. Our current observations and analyses suggest that the tunability of the macroscopic CTE through thermo-mechanical processing is universal in materials - both ceramic and metals - that undergo martensitic transformations.
\end{abstract}

Keywords: Coefficient of thermal expansion; Negative coefficient of thermal expansion; Martensitic transformation; Shape memory alloys; Anisotropy 


\section{INTRODUCTION}

Control of thermal expansion mismatch is a critical goal of engineering design in a wide range of applications, particularly in cases where system components are small, are subject to large changes (gradients) in temperatures, or require extreme dimensional stability over a wide range of temperatures. Thermal expansion compensation often requires materials with either negative or (close to) zero thermal expansion (NTE or ZTE, respectively). The most widely known mechanisms that yield negative thermal expansion (NTE) include the magneto-volume effect, atomic radius contraction upon electronic transitions and flexible networks [1]. The magneto-volume effect, first discovered in 1897 [1], is found in FeNi-based Invar alloys that are widely used for thermal expansion compensation due to its high strength and ductility. Invar's low thermal expansion originates from instabilities between different magnetic configurations that at the same time result in significant magnetostriction effects [2, 3]. Recently, clear links have been made between the magneto-volume effect and the martensitic phase transformations exhibited by FeNi alloys [3, 4]. In these systems, only compositional changes that affect magnetic ordering and unit cell volume can tailor Invar's thermal expansion characteristics.

Another mechanism for NTE is encountered in $\mathrm{Sm}_{2.75} \mathrm{C}_{60}$, one of the materials with the largest known NTE. In this case, the observed NTE arises from atomic radius contraction due to valence electron exchange. Unfortunately, this effect only occurs below $32 \mathrm{~K}$ [5] and is therefore of limited technological value. Other material systems exhibit NTE through atomic rotations and transverse atomic vibrations in flexible networks that occupy different atomic configurations with increasing temperature. For example, the $\mathrm{ZrW}_{2} \mathrm{O}_{8}$ [6-8] and $\mathrm{ReO}_{3}$ families of ceramics show isotropic NTE via octahedral site rotations that cause uniform contraction in the cubic unit cell. Transverse atomic vibrations in non-cubic crystalline metal oxides (such as $\mathrm{Mg}_{2} \mathrm{Al}_{4} \mathrm{Si}_{5} \mathrm{O}_{18}$ 
cordierite $[9,10], \mathrm{LiAlSiO}_{4} \beta$-eucriptite $[9,10], \mathrm{NaZr}_{2} \mathrm{P}_{3} \mathrm{O}_{12}[9,10]$ and $\mathrm{PbTiO}_{3}$ perovskite [10]) and carbon structures [11] (such as graphite, carbon fibers and nano-tubes) result in NTE in certain material directions and positive thermal expansion (PTE) in others. Unfortunately, the application potential of NTE ceramics is limited due to their low fracture toughness [12], low thermal conductivity, and the need for chemical composition changes to tailor their coefficient of thermal expansion (CTE). While carbon reinforced composites are a more attractive alternative for tailored thermal expansion compensation, harnessing carbon's low CTE requires complex and expensive composite fabrication techniques.

In this work, a new method for easily tailoring the thermal expansion coefficient of alloys that exhibit martensitic transformation by harnessing their giant NTE and PTE associated with different crystallographic directions is presented. Interestingly, the NTE and PTE directions are not solely related to the martensite's crystal symmetry, but can be predicted by comparing the high temperature austenite phase's lattice parameters with the low temperature martensite's lattice parameters. While the fundamental nature of this anisotropic thermal expansion is currently not understood, this simple correspondence successfully predicts the PTE and NTE directions of not only martensitic metals and alloys such as NiTiPd, TiNb, CoNiGa, NiTi [13], and $\alpha$-Uranium [14], but also functional ceramics such as $\mathrm{PbTiO}_{3}$ that undergo martensitic transformation. These different materials represent various crystallographic symmetries, composition, chemical ordering, and bonding types while sharing martensitic transformation and thermal expansion anisotropy. The ability to tailor an alloy's CTE using simple mechanical deformation promises exceptional control over thermal expansion compensation design in the automotive, aerospace, marine, electronic, power generation and transmission, and scientific instrumentation industries. 


\section{Experimental Procedures}

We selected three different alloy systems exhibiting martensitic transformation in order to demonstrate the CTE anisotropy of martensitic alloys regardless of the crystal structure of martensite, or whether the alloy is ordered or not. In addition, we show that different, but simple thermo-mechanical processing methods can be used to tailor the CTE of these alloys between large positive and large negative values, by crystallographically texturing martensite through martensite reorientation / detwinning mechanisms. These alloy systems are $\mathrm{Ni}_{19.5} \operatorname{Ti}_{50.5} \mathrm{Pd}_{30}$ in polycrystalline form, $\mathrm{Co}_{49} \mathrm{Ni}_{21} \mathrm{Ga}_{30}$ as single crystals, and $\mathrm{Ti}_{78} \mathrm{Nb}_{22}$ in polycrystalline form. Figure 1 displays the comparison between the austenite, blue, and martensite, green, phases for these three alloys. The three alloys were selected as representative systems to illustrate the universal nature of the CTE anisotropy and tailorable CTE in martensitic materials. Using Figure 1, the lattice parameter correspondence between austenite and martensite will be shown to correlate with the observed thermal expansion anisotropy below.

$\mathrm{Co}_{49} \mathrm{Ni}_{21} \mathrm{Ga}_{30}$ single crystal samples were grown in a He environment using the Bridgman technique. $4 \times 4 \times 8 \mathrm{~mm}$ samples were wire electro-discharge machined (EDMed) from the larger single crystals and etched to remove the EDM recast layer. The samples were then homogenized at $1473 \mathrm{~K}$ for $4 \mathrm{hrs}$, followed by water quenching (WQ) under ultra-high purity (UHP) argon in quartz ampules. These samples were mostly used for neutron diffraction experiments in order to

demonstrate the CTE anisotropy in an example tetragonal $\left(\mathrm{L} 1_{0}\right)$ martensite system. For the NiTiPd alloy, the ingots with the composition of $\mathrm{Ni}_{19.5} \mathrm{Ti}_{50.5} \mathrm{Pd}_{30}$ were vacuum induction melted in a graphite crucible and cast into a water cooled copper mold. The ingots were homogenized and encased in a steel can prior to $900^{\circ} \mathrm{C}$ extrusion with a 7 to 1 reduction in area. Dog-bone tension samples were then wire EDMed from the extruded rods for tensile processing. Elemental 
$\mathrm{Ti}$ and $\mathrm{Nb}$ were arc melted under argon gas to obtain samples with the composition of $\mathrm{Ti}_{78} \mathrm{Nb}_{22}$. The ingot was then sealed in a quartz tube under UHP argon and heat treated at $1273 \mathrm{~K}$ for 24 hrs. $0.5 \mathrm{~mm}$ thick $\mathrm{Ni}_{19.5} \mathrm{Ti}_{50.5} \mathrm{Pd}_{30}$ and $\mathrm{Ti}_{78} \mathrm{Nb}_{22}$ samples were wire $\mathrm{EDM}$ cut and polished to a mirror finish prior to the diffraction experiments.

Lattice parameters for $\mathrm{Ni}_{19.5} \mathrm{Ti}_{50.5} \mathrm{Pd}_{30}$ and $\mathrm{Ti}_{78} \mathrm{Nb}_{22}$ were determined at discrete temperatures using x-ray diffraction (XRD), while $\mathrm{Co}_{49} \mathrm{Ni}_{21} \mathrm{Ga}_{30}$ was characterized using neutron diffraction. During the diffraction experiments, all samples were first cooled to the lowest diffraction temperature and heated to each subsequent measurement temperature. XRD was conducted using $\mathrm{Cu}$ K- $\alpha$ radiation on a Bruker AXS X-Ray Diffractometer with a hot stage fitted with a platinum heating strip. Temperature was controlled and measured using a thermocouple fixed to the sample's surface. The lattice parameters were determined using TOPAZ software by fitting a pseudo-Voigt function to individual XRD peaks and using Bragg's law to calculate the atomic plane spacing. Texture analysis was also performed on the $0 \%, 25 \%$ and $50 \%$ rolled $\mathrm{Ti}_{78} \mathrm{Nb}_{22}$ samples. A three axis goniometer stage in the Bruker AXS Diffractometer was used to rotate the sample. Inverse pole figures were created from the texture data using MTEX data analysis code.

Neutron diffraction was conducted using the Spectrometer for Materials Research at Temperature and Stress (SMARTS) instrument [15] and the High Intensity Powder Diffractometer (HIPD) at the Lujan Neutron Scattering Center at the Los Alamos Neutron Science Center (LANSCE). The Lujan Center is a pulsed spallation source of a "white" neutron beam. SMARTs and HIPD operate on a $10^{\circ} \mathrm{C}$ water moderator providing useful neutrons in the range of 0.5 to $4 \AA$. Sample cooling on SMARTS was achieved under vacuum using a helium closed-cycle refrigerator (CCR) capable of reaching temperatures down to 50K. Sample cooling 
on HIPD was achieved down to $4 \mathrm{~K}$ using a similar CCR with He exchange gas. Time of flight (TOF) data was collected on stationary detector banks comprised of ${ }^{3} \mathrm{He}$ fill aluminum tubes. Lattice spacing was determined by single peak fits of the TOF data using the rawplot subroutine [16] of the General Structure Analysis System (GSAS) software developed at Los Alamos [17]. The materials d-spacing at various temperatures was used to calculate the thermal lattice strain along specific crystal orientations and determine the thermal expansion anisotropy.

For thermal expansion tensor calculations, the Lagrangian or engineering thermal expansion $(\alpha)$ along any unit vector (ni) in a solid is given by:

$$
\alpha \equiv 1 \mathrm{lo} \partial \mathrm{l} \partial \mathrm{T}=\partial \varepsilon \partial \mathrm{T}=\alpha \mathrm{ijninj}
$$

where lo is the original material length along ni, $\mathrm{l}$ is the temperature dependent material length along ni, $\varepsilon$ is the thermally induced lattice strain along ni, and $\alpha \mathrm{ij}$ is the thermal expansion tensor. $\alpha \mathrm{ij}$ is anisotropic in crystalline structures with their respective forms given by Ref. [18]. By setting ni parallel to the plane normals and $\mathrm{l}$ equal to the planar spacing, the temperature dependent lattice spacing can be used to calculate $\alpha$ along different crystallographic directions. The best way to determine lattice spacing is through x-ray or neutron diffraction experiments where each diffraction peak represents the distance between crystallographic planes. While the minimum number of diffraction peaks required to determine the complete thermal expansion tensor is equal to the number of independent thermal expansion components of $\alpha$, a least squares refinement of several peaks is preferred [13] to increase accuracy. The corresponding thermal expansion tensor components for each material studied in this work are presented in the next section. 
Processing to achieve tailored thermal expansion was conducted on $\mathrm{Ni}_{19.5} \mathrm{Ti}_{50.5} \mathrm{Pd}_{30}$ by pulling in tension and $\mathrm{Ti}_{78} \mathrm{Nb}_{22}$ by room temperature rolling. Tensile processing was achieved by incremental strain tests on a servo-hydraulic MTS test frame and the thermal expansion response was measured at each deformation increment. Displacement was measured using an MTS high temperature extensometer fitted with ceramic extension rods in direct contact with the sample. Heating and cooling was achieved by conduction through the grips. Copper coils were wrapped around the grips to flow liquid nitrogen for cooling and band heaters around the coils for heating. The homogenized $\mathrm{Ti}_{78} \mathrm{Nb}_{22}$ ingot was wire EDM cut into $4 \mathrm{~mm}$ thick coins and subsequently rolled to $20 \%, 50 \%$ and $80 \%$ thickness reduction at room temperature. $5 \mathrm{~mm}$ long compression samples were wire EDM cut along the rolling and transverse sample directions for thermal expansion measurement on a TA Instruments Thermo-Mechanical Analyzer (TMA).

\section{Experimental Results}

\section{Thermal Expansion Anisotropy}

The thermal expansion of the respective martensitic crystal structures of the $\mathrm{Ni}_{19.5} \mathrm{Ti}_{50.5} \mathrm{Pd}_{30}, \mathrm{Ti}_{78} \mathrm{Nb}_{22}$ and $\mathrm{Co}_{49} \mathrm{Ni}_{21} \mathrm{Ga}_{30}$ alloys was determined by measuring the lattice spacing at various temperatures using x-ray and neutron diffraction measurements. Figure 2 displays the diffraction patterns of $\mathrm{Ni}_{19.5} \mathrm{Ti}_{50.5} \mathrm{Pd}_{30}$ at $300 \mathrm{~K}, \mathrm{Ti}_{78} \mathrm{Nb}_{22}$ at $300 \mathrm{~K}$, and $\mathrm{Co}_{49} \mathrm{Ni}_{21} \mathrm{Ga}_{30}$ at $4 \mathrm{~K}$ highlighting reflections for the orthorhombic B19, orthorhombic disordered and tetragonal $\mathrm{L1}_{0}$ martensites, respectively. The strains $\varepsilon \mathrm{T}=\mathrm{lT}-$ lolo between different lattice planes for $\mathrm{Co}_{49} \mathrm{Ni}_{21} \mathrm{Ga}_{30}, \mathrm{Ti}_{78} \mathrm{Nb}_{22}$ and $\mathrm{Ni}_{19.5} \mathrm{Ti}_{50.5} \mathrm{Pd}_{30}$ are displayed in Figure 3 with lo taken from the diffraction patterns in Figure 2. The markers correspond to the data points taken from several planar spacing reflections. All the experimental temperatures are below the martensitic 
transformation finish temperature for each material, i.e. $316 \mathrm{~K}$ for $\mathrm{Co}_{49} \mathrm{Ni}_{21} \mathrm{Ga}_{30}$ [19], 500K for $\mathrm{Ti}_{78} \mathrm{Nb}_{22}$ [20] and 500K for $\mathrm{Ni}_{19.5} \mathrm{Ti}_{50.5} \mathrm{Pd}_{30}$ [21]. The $\mathrm{Ni}_{19.5} \mathrm{Ti}_{50.5} \mathrm{Pd}_{30}$ response is linear within the measurement uncertainty in the studied temperature range with expansion between the (100) planes and contraction between the (020) and (002) planes. The distances between the (110), (310) and (301) $\mathrm{Co}_{49} \mathrm{Ni}_{21} \mathrm{Ga}_{30}$ planes increase while those between the (103) planes decreases and the distance between the (101) planes does not change. The $\mathrm{Ti}_{78} \mathrm{Nb}_{22}$ 's (020), (130), (021) and (022) planes contract while the (002) and (111) planes expand with increasing temperature. Second order polynomial fits of the $\mathrm{Co}_{49} \mathrm{Ni}_{21} \mathrm{Ga}_{30}$ and $\mathrm{Ti}_{78} \mathrm{Nb}_{22}$ strain data and linear fits of the $\mathrm{Ni}_{19.5} \mathrm{Ti}_{50.5} \mathrm{Pd}_{30}$ strain data, solid lines in Figure 3, were used to determine the components of the thermal expansion tensors. Table 1 displays the experimentally measured thermal expansion coefficients along martensite's principal crystallographic directions of [100], [010] and [001], corresponding to martensite's $\alpha 11, \alpha 22$ and $\alpha 33$, respectively.

Figures 4A-C display the CTE magnitudes for (A) $\mathrm{Ni}_{19.5} \mathrm{Ti}_{50.5} \mathrm{Pd}_{30}$, (B) $\mathrm{Co}_{49} \mathrm{Ni}_{21} \mathrm{Ga}_{30}$ at $260 \mathrm{~K}$, and (C) $\mathrm{Ti}_{78} \mathrm{Nb}_{22}$ at $473 \mathrm{~K}$, determined from the thermal expansion measurements displayed in Figure 3. The green and blue ellipsoids correspond to positive and negative thermal expansion values, respectively. The orthorhombic $\mathrm{Ni}_{19.5} \mathrm{Ti}_{50.5} \mathrm{Pd}_{30}$ alloy exhibits positive thermal expansion along the [100] direction and negative thermal expansion along the [001] direction. $\mathrm{Ni}_{19.5} \operatorname{Ti}_{50.5} \mathrm{Pd}_{30}$ 's [010] direction has a very small negative thermal expansion. The tetragonal $\mathrm{Co}_{49} \mathrm{Ni}_{21} \mathrm{Ga}_{30}$ alloy exhibits uniform positive thermal expansion along the [100] and [010] directions and negative thermal expansion along the [001] direction. While $\mathrm{Ti}_{78} \mathrm{Nb}_{22}$ shares its orthorhombic crystal symmetry with $\mathrm{Ni}_{19.5} \mathrm{Ti}_{50.5} \mathrm{Pd}_{30}$, it only shows contraction along the [010] axis and expansion along the [100] and [001] axes. This indicates that the crystal symmetry is not the only factor that influences the thermal expansion anisotropy in these martensitic alloys. 
While they may have different values, the thermal expansion values inherit the symmetry of the crystal phase with the orthorhombic $\mathrm{Ti}_{78} \mathrm{Nb}_{22}$ and $\mathrm{Ni}_{19.5} \mathrm{Ti}_{50.5} \mathrm{Pd}_{30}$ having different values in each crystallographic direction and the tetragonal $\mathrm{Co}_{49} \mathrm{Ni}_{21} \mathrm{Ga}_{30}$ being isotropic in the [100]-[010] plane. The largest magnitudes of positive and negative thermal expansion are $\mathrm{Ti}_{78} \mathrm{Nb}_{22}$ 's giant $+18110^{-6} \mathrm{~K}^{-1}$ and $-14210^{-6} \mathrm{~K}^{-1}$ at $473 \mathrm{~K}$.

\section{Tailored Thermal Expansion}

The giant thermal expansion anisotropy observed at the atomic level can be leveraged to tune the alloys' macroscopic thermal expansion through control of the crystallographic texture via thermo-mechanical deformation. Figure 5A shows the stress-strain response of $\mathrm{Ni}_{19.5} \mathrm{Ti}_{50.5} \mathrm{Pd}_{30}$ as the sample is loaded, unloaded, and loaded again, under tension, at room temperature. In between each incremental loading-unloading cycle, the sample was thermally cycled within the martensitic phase under zero stress to obtain the bulk samples' macroscopic thermal expansion characteristics. Figure 5B displays the macroscopic strain vs. temperature response for the polycrystalline $\mathrm{Ni}_{19.5} \mathrm{Ti}_{50.5} \mathrm{Pd}_{30}$ strained incrementally between $0 \%$ and $5 \%$ tensile strain in Figure 5A. The 0\% strained condition expands with increasing temperature as expected from traditional alloys. Increasing the pre-strain from $1 \%$ to $4 \%$ strain decreases the material's dependence on temperature as the CTE approaches zero. At 5\% strain, the response crosses from positive thermal expansion to negative thermal expansion at the macroscopic scale. A similar decrease in CTE is observed for cold rolled $\mathrm{Ti}_{78} \mathrm{Nb}_{22}$ along the rolling direction as displayed in Figure 5C. The $0 \%$ rolled sample has a normal positive thermal expansion response while increasing deformation percent from $20 \%$ to $80 \%$ decreases the thermal expansion values to large negative magnitudes. 
The resulting thermal expansion coefficients vs. induced deformation percent are shown in Figure 6A for $\mathrm{Ni}_{19.5} \mathrm{Ti}_{50.5} \mathrm{Pd}_{30}$ and Figure 6B for $\mathrm{Ti}_{78} \mathrm{Nb}_{22}$. The $\mathrm{Ni}_{19.5} \mathrm{Ti}_{50.5} \mathrm{Pd}_{30}$ linear CTE decreases with increasing imposed strain and ultimately exhibits negative thermal expansion at the macroscopic scale. The thermal expansion along the rolling, transverse and normal sample directions are displayed for $\mathrm{Ti}_{78} \mathrm{Nb}_{22}$. The rolling direction's CTE decreases asymptotically from $9 \times 10^{-6} \mathrm{~K}^{-1}$ to $-40 \times 10^{-6} \mathrm{~K}^{-1}$. The transverse and normal directions both increase with increasing deformation with the normal direction changing the most from $9 \times 10^{-6} \mathrm{~K}^{-1}$ to $50 \times 10^{-6} \mathrm{~K}^{-1}$. It should be noted that the reason for the apparent decrease in CTE with the $80 \%$ rolled sample measurement along the normal direction is not currently known, further diffraction studies on the samples rolled to different thickness reductions are underway to reveal the potential reasons.

\section{Discussion of the Results}

In addition to $\mathrm{Ni}_{19.5} \mathrm{Ti}_{50.5} \mathrm{Pd}_{30}, \mathrm{Ti}_{78} \mathrm{Nb}_{22}$ and $\mathrm{Co}_{49} \mathrm{Ni}_{21} \mathrm{Ga}_{30}$ material systems presented above, some other material systems known to exhibit NTE and PTE anisotropic thermal expansion below their martensitic transformation temperatures are thermo-elastic alloys and ceramics, such as NiTi [13] and $\mathrm{PbTiO}_{3}$ [10], and non-thermo-elastic $\alpha$-Uranium [14]. These and the materials studied in this work represent pure metals (U), disordered alloys (TiNb), B2 ordered alloys (NiTi and NiTiPd), Heusler alloys (CoNiGa), and ceramics $\left(\mathrm{PbTiO}_{3}\right)$. Table 1 lists the experimentally determined thermal expansion along martensite's crystallographic directions from diffraction experiments with NTE values highlighted in red. The two tetragonal crystal structures, $\mathrm{Co}_{49} \mathrm{Ni}_{21} \mathrm{Ga}_{30}$ and $\mathrm{PbTiO}_{3}$, exhibit contraction along the [001] direction and expansion along the [100] and [010] directions while the monoclinic material, NiTi, exhibits NTE only along the [100] direction. The three orthorhombic materials show different behavior from each 
other with $\mathrm{Ni}_{19.5} \mathrm{Ti}_{50.5} \mathrm{Pd}_{30}$ contracting along the [100] and [010] directions while $\mathrm{U}$ and $\mathrm{Ti}_{78} \mathrm{Nb}_{22}$ contract only along [010].

Aside from PTE and NTE anisotropy, a common thread between these various materials is the martensitic transformation. A martensitic transformation is a diffusionless solid-solid phase transformation between a high temperature austenite phase and a low temperature martensite phase. The austenite phase in all these materials has cubic symmetry that exhibits isotropic PTE while the martensite phase has lower symmetry, such as tetragonal; orthorhombic; or monoclinic, and exhibits PTE and NTE anisotropy along different crystallographic directions. The correspondence between these two crystal phases (i.e. austenite and martensite) can be determined using a simple rotation matrix, $\mathrm{RA} \rightarrow \mathrm{M}$ presented in Table 2, that maps distances from austenite's to martensite's principal coordinate system. These rotation matrices will be used to compare austenite and martensite lattice parameters below.

The lattice parameters for the high temperature austenite, lA, and low temperature martensite, $\mathrm{lM}$, phases of these five different materials are presented in Table 1 along with a lattice parameter comparison $\mathrm{RA} \rightarrow \mathrm{MlA}-\mathrm{IM}$ along the given crystallographic directions. For all materials presented, the martensite's crystallographic NTE directions correspond to the crystallographic directions that are smaller in austenite than martensite, i.e. where $\mathrm{RA} \rightarrow \mathrm{MlA}<\mathrm{lM}$, and PTE directions correspond to directions that are larger in austenite than martensite, i.e. where $\mathrm{RA} \rightarrow \mathrm{MlA}>\mathrm{IM}$. This criteria can be observed graphically by comparing the austenitemartensite lattice schematics for $\mathrm{CoNiGa}$, NiTiPd and $\mathrm{TiNb}$ displayed in Figure 1. The difference in angle, $\beta A-\beta M$, was also determined for monoclinic NiTi. The directions with negative values of $\mathrm{RA} \rightarrow \mathrm{MlA}<\mathrm{lM}$ (shown in red) are those that experimentally exhibit NTE and vice versa. The existence of positive and negative thermal expansion anisotropy in this wide 
variety of material systems and its connection to the austenite-martensite lattice parameter correspondence points to a mechanism potentially linked to the martensitic transformation. This observation also suggests that the Invar effect recently discovered in cold rolled $\mathrm{Ti}_{23} \mathrm{Nb}_{0.7} \mathrm{Ta}_{2} \mathrm{Zr}_{1.2} \mathrm{O}$ alloys may be a result of stress induced martensite in addition to the strain glass transition as described in [22].

The tailored directional macroscopic CTE responses are achieved here by orienting the martensite variants along the sample directions via thermo-mechanical deformation. Figure 7 displays inverse pole figures along the rolling, transverse and normal directions of $\mathrm{Ti}_{78} \mathrm{Nb}_{22}$ at $0 \%, 20 \%$ and $50 \%$ rolling deformation. The $0 \%$ rolled material shows nearly random weak texture with martensite variants mostly randomly oriented within the sample. This is corroborated by the isotropic macroscopic CTE exhibited by the $0 \%$ rolled condition in Figure 6. The 50\% rolled condition on the other hand exhibits strong (010) texture along the rolling direction, (307) texture in the transverse direction and (101) texture along the normal direction. The $\mathrm{Ti}_{78} \mathrm{Nb}_{22}$ crystal's largest negative thermal expansion direction is [010], as shown in Figure 4C. The intensity of (010) poles along the sample's rolling direction increases with higher rolling reduction. Therefore, the lattice level negative thermal expansion in Table 1 and Figure 3, creates the negative thermal expansion observed at the macroscopic scale, Figure 5C. The [307] and [101] directions exhibit positive thermal expansion with the [101] direction having a larger CTE magnitude than [307], as shown in Figure 4C. This correlates strongly with the textures observed in the transverse and normal sample directions, respectively. The transverse and normal directions exhibit positive thermal expansion at all rolling deformation levels. The transverse direction's CTE increases with increasing deformation, but remains smaller in magnitude than 
the normal direction's CTE. As a result of the texturing process, the macroscopic thermal expansion of this material is "programmed" or tuned by the rolling deformation.

Figure 8 displays the linear thermal expansion coefficient vs. thermal conductivity for various material types. Highlighted in purple is the current thermal expansion region that a single crystal martensitic material could potentially exhibit. The thermal expansion characteristics for this new class of tailored thermal expansion alloys can match those of polymers, ceramics and other metals over a much wider range than composite materials. The thermal expansion anisotropy is key to obtaining a tailored thermal expansion coefficient in a single material without changing the chemical composition. This is a response that materials exhibiting isotropic thermal expansion characteristics, such as Invar and $\mathrm{ZrW}_{2} \mathrm{O}_{8}$, cannot achieve. This new approach for tailoring CTEs in bulk materials can provide the means to tightly control a metal's thermal expansion response beyond any currently known material, without the tradeoffs associated with changing material composition or complex composite fabrication. More importantly, the decoupling between composition and macroscopic CTE dramatically increases the materials design space as composition could potentially be adjusted to meet specific functional requirements not necessarily related to the need to compensate thermal expansion.

\section{Conclusions}

In conclusion, the controlled crystallographic texturing of martensite variants can be used to tailor the thermal expansion response of martensitic materials through simple thermo-mechanical processing. In principle, any texturing method could be used to tune the macroscopic thermal expansion coefficient of these materials. This ability to control the CTE of these materials through texture is associated with the highly anisotropic nature of the thermal expansion tensor 
in the martensite phase. It was also shown that NTE or PTE crystallographic directions were connected to the crystallographic relationship between the austenite and martensite lattices, pointing to a possible mechanism linked to the martensitic transformation shared by these materials. It is believed that these criteria can be applied to a much wider range of materials that undergo martensitic transformation, although there is still much to be understood about the fundamental physical basis for the observed phenomenon. The degree of control over the macroscopic thermal expansion response of the materials presented in this work suggests a revolutionary and inexpensive approach to tune the CTE of materials for use in applications that are sensitive to temperature changes or gradients.

\section{Acknowledgements:}

This work was supported by National Science Foundation, Division of Materials Research, Metals and Metallic Nanostructures Program, Grant No. 0909170, and additional support was received from the National Science Foundation under Grant No. DMR 08-44082, which supports the International Materials Institute for Multi-functional Materials for Energy Conversion (IIMEC) at Texas A\&M University. The work has also benefited from the use of SMARTS and HIPD at the Lujan Center at Los Alamos Neutron Science Center, funded by the US Department of Energy's Office of Basic Energy Sciences. Los Alamos National Laboratory is operated by Los Alamos National Security LLC under US DOE Contract DE-AC5206NA25396. The authors thank Dr. Trudy Kriven and Kevin Seymour from the University of Illinois at Urbana-Champaign for the use of their Coefficient of Thermal Expansion Analysis Suite (CTEAS). 


\section{References}

[1] K. Takenaka, Negative thermal expansion materials: technological key for control of thermal expansion. Sci. Technol. Adv. Mat. 13 (2012).

[2] R. J. Weiss, The Origin of the 'Invar' Effect. P. Phys. Soc. 82 (1963) 281.

[3] E. F. Wassermann, The Invar problem. J. Magn. Magn. Mater. 100 (1991) 346-362.

[4] P. Entel, E. Hoffmann, P. Mohn, K. Schwarz, V. L. Moruzzi, First-principles calculations of the instability leading to the Invar effect. Phys. Rev. B 47 (1993) 8706-8720.

[5] J. Arvanitidis, K. Papagelis, S. Margadonna, K. Prassides, A. N. Fitch, Temperatureinduced valence transition and associated lattice collapse in samarium fulleride. Nature 425 (2003) 599-602.

[6] J. S. O. Evans, T. A. Mary, T. Vogt, M. A. Subramanian, A. W. Sleight, Negative Thermal Expansion in $\mathrm{ZrW}_{2} \mathrm{O}_{8}$ and $\mathrm{HfW}_{2} \mathrm{O}_{8}$. Chem. Mater. 8 (1996) 2809-2823.

[7] T. A. Mary, J. S. O. Evans, T. Vogt, A. W. Sleight, Negative Thermal Expansion from 0.3 to 1050 Kelvin in $\mathrm{ZrW}_{2} \mathrm{O}_{8}$. Science 272 (1996) 90-92.

[8] A. W. Sleight, Thermal contraction. Nature 389 (1997) 923-924.

[9] A. W. Sleight, Thermal Contraction. Endeavour 19 (1995) 64-68.

[10] A. W. Sleight, Compounds that contract on heating. Inorg. Chem. 37 (1998) 2854-2860.

[11] P. K. Schelling, P. Keblinski, Thermal expansion of carbon structures. Phys. Rev. B 68 (2003) 035425. 
[12] V. Srikanth, E.C. Subbarao, D.K. Agrawal, C.-Y. Huang, R. Roy, G.V. Rao, Thermalexpansion anisotropy and acosutic-emission of $\mathrm{NaZr}_{2} \mathrm{P}_{3} \mathrm{O}_{12}$ family ceramics. J. Am. Ceram. Soc. 74 (1991) 365-368.

[13] S. Qiu, V.B. Krishnan, S.A. Padula II, R.D. Noebe, D.W. Brown, B. Clausen, R. Vaidyanathan, Measurement of the lattice plane strain and phase fraction evolution during heating and cooling in shape memory NiTi. Appl. Phys. Lett. 95 (2009).

[14] L. T. Lloyd, C. S. Barrett, Thermal expansion of alpha uranium. J. Nucl. Mater. 18 (1966) 55.

[15] M. A. M. Bourke, D. C. Dunand, E. Ustundag, SMARTS - a spectrometer for strain measurement in engineering materials. Appl. Phys. A 74 (2002) s1707-s1709.

[16] B. Clausen, Los Alamos National Laboratory, LA-UR 04-6581, 2004, Los Alamos, NM.

[17] R.B. Vondreele, J.D. Jorgensen, C.G. Windsor, Rietveld refinement with spallation neutron powder diffraction data, J. App. Crys., 15 (1982) 581-589.

[18] J. L. Schlenker, G. V. Gibbs, M. B. Boisen, Thermal-expansion coefficients for Monoclinic Crystals - Phenomenological Approach. Am. Mineral. 60 (1975) 828-833.

[19] E. Dogan, I. Karaman, N. Singh, A. Chivukula, H.S. Thawabi, R. Arroyave, The effect of electronic and magnetic valences on the martensitic transformation of CoNiGa shape memory alloys. Acta Mater. 60 (2012) 3545-3558.

[20] H. Y. Kim, Y. Ikehara, J. I. Kim, H. Hosoda, S. Miyazaki, Martensitic transformation, shape memory effect and superelasticity of Ti-Nb binary alloys. Acta Mater. 54 (2006) 2419-2429.

[21] J.A. Monroe, I. Karaman, D.C. Lagoudas, G. Bigelow, R.D. Noebe, S. Padula II, Determining recoverable and irrecoverable contributions to accumulated strain in a 
NiTiPd high-temperature shape memory alloy during thermomechanical cycling. Scripta Mater. 65 (2011) 123-126.

[22] Y. Wang, J. Gao, H. Wu, S. Yang, X. Ding, D. Wang, X. Ren, Y. Wang, X. Song, J. Gao, Strain glass transition in a multifunctional $\beta$-type Ti alloy. Sci. Rep. 4 (2014). 

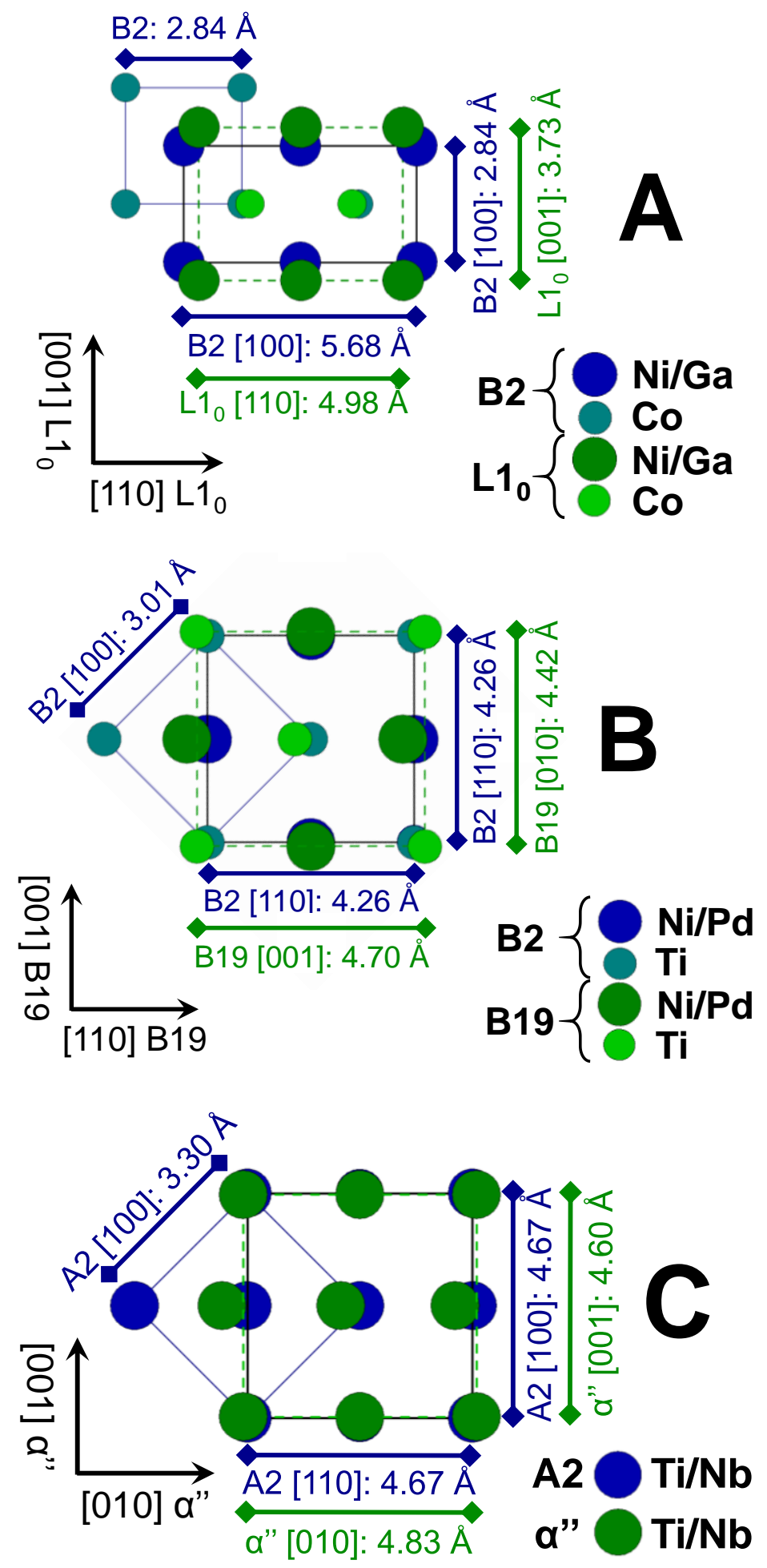

Figure 1. Crystallographic relationships between cubic austenite (ordered $\mathrm{B} 2 \mathrm{CoNiGa}(\mathrm{A})$ and NiTiPd (B) and disordered A2 TiNb (C)), and martensite (ordered tetragonal $\mathrm{L}_{0} \mathrm{CoNiGa}(\mathrm{A})$, ordered orthorhombic B19 NiTiPd (B), and disordered orthorhombic $\alpha$ " TiNb (C)) of the materials studied in the present work. 


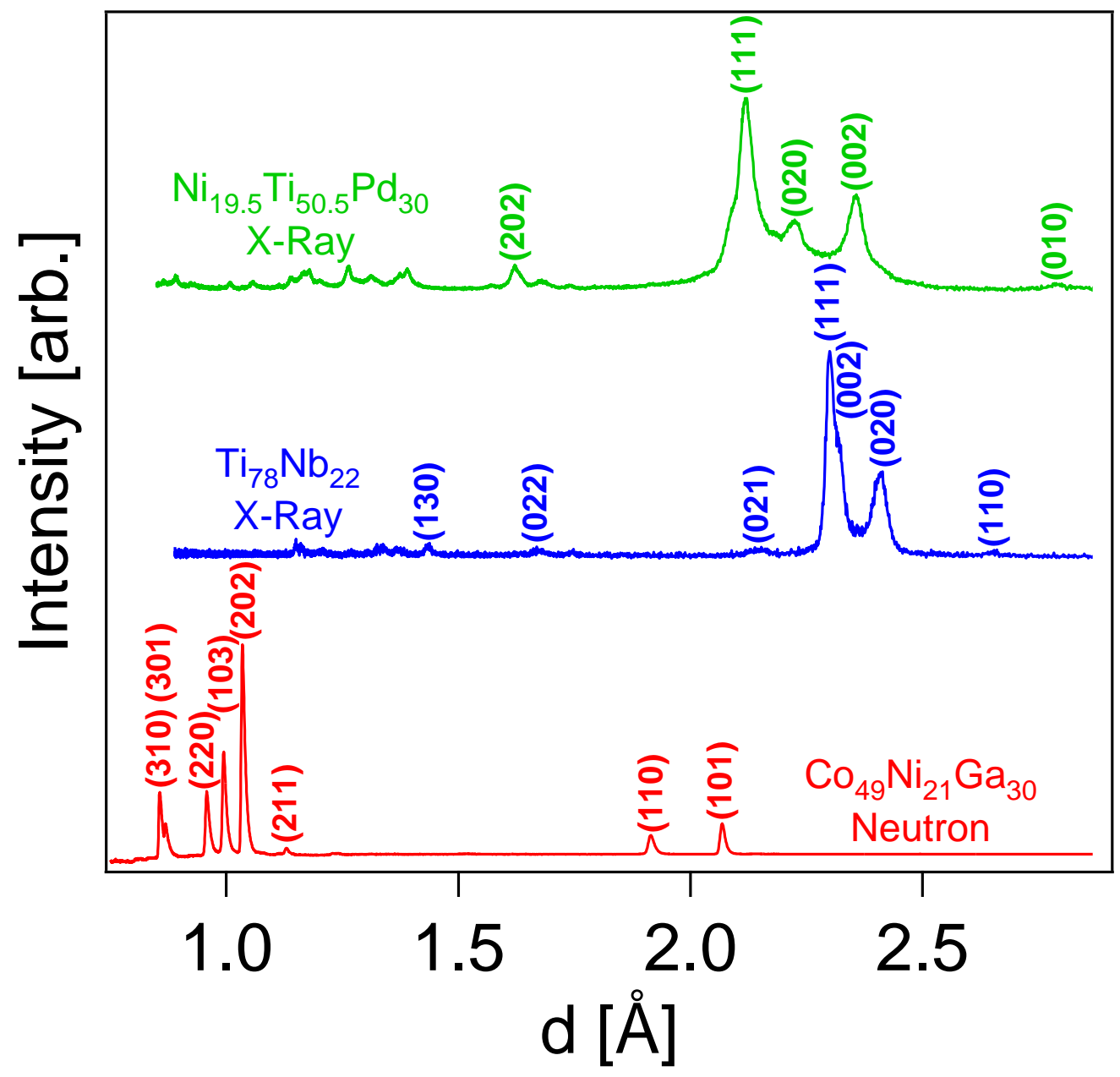

Figure 2. Indexed diffraction patterns for $\mathrm{Ni}_{19.5} \mathrm{Ti}_{50.5} \mathrm{Pd}_{30}$ and $\mathrm{Ti}_{78} \mathrm{Nb}_{22}$ martensite phases at $300 \mathrm{~K}$ from the XRD experiments and $\mathrm{Co}_{49} \mathrm{Ni}_{21} \mathrm{Ga}_{30}$ martensite at $4 \mathrm{~K}$.The martensite phase structures are ordered B19 orthorhombic for NiTiPd, disordered orthorhombic for TiNb, and $\mathrm{L}_{0}$ for CoNiGa. 

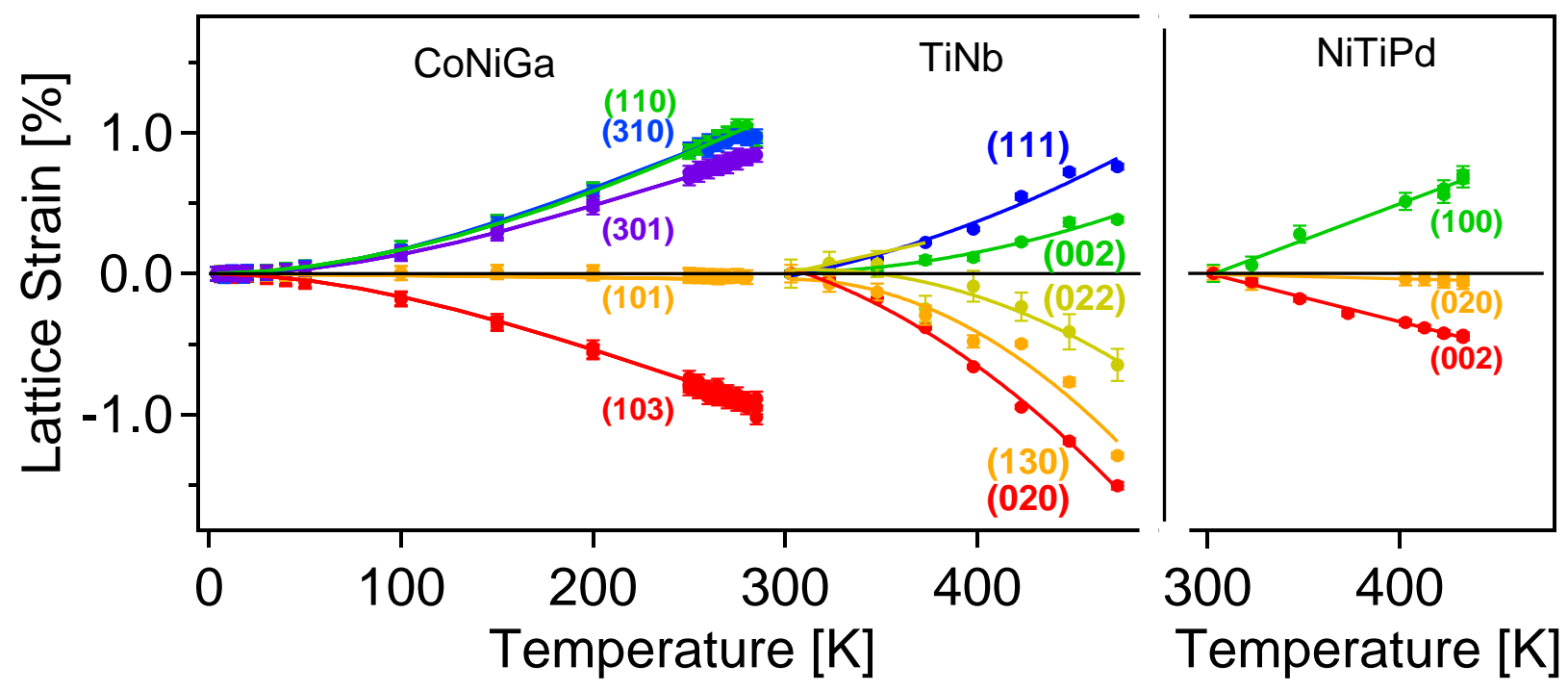

Figure 3. Thermal expansion along different crystallographic planes in the three different alloys in the present study. Lattice strains between different crystallographic planes are shown for martensitic $\mathrm{Co}_{49} \mathrm{Ni}_{21} \mathrm{Ga}_{30}$ between $4 \mathrm{~K}-285 \mathrm{~K}, \mathrm{Ti}_{78} \mathrm{Nb}_{22}$ between $303 \mathrm{~K}-473 \mathrm{~K}$, and $\mathrm{Ni}_{19.5} \mathrm{Ti}_{50.5} \mathrm{Pd}_{30}$ between $303 \mathrm{~K}-433 \mathrm{~K}$, based on their transformation temperatures from martensite to austenite, which dictate the highest temperature the martensite lattice strains can be determined. 

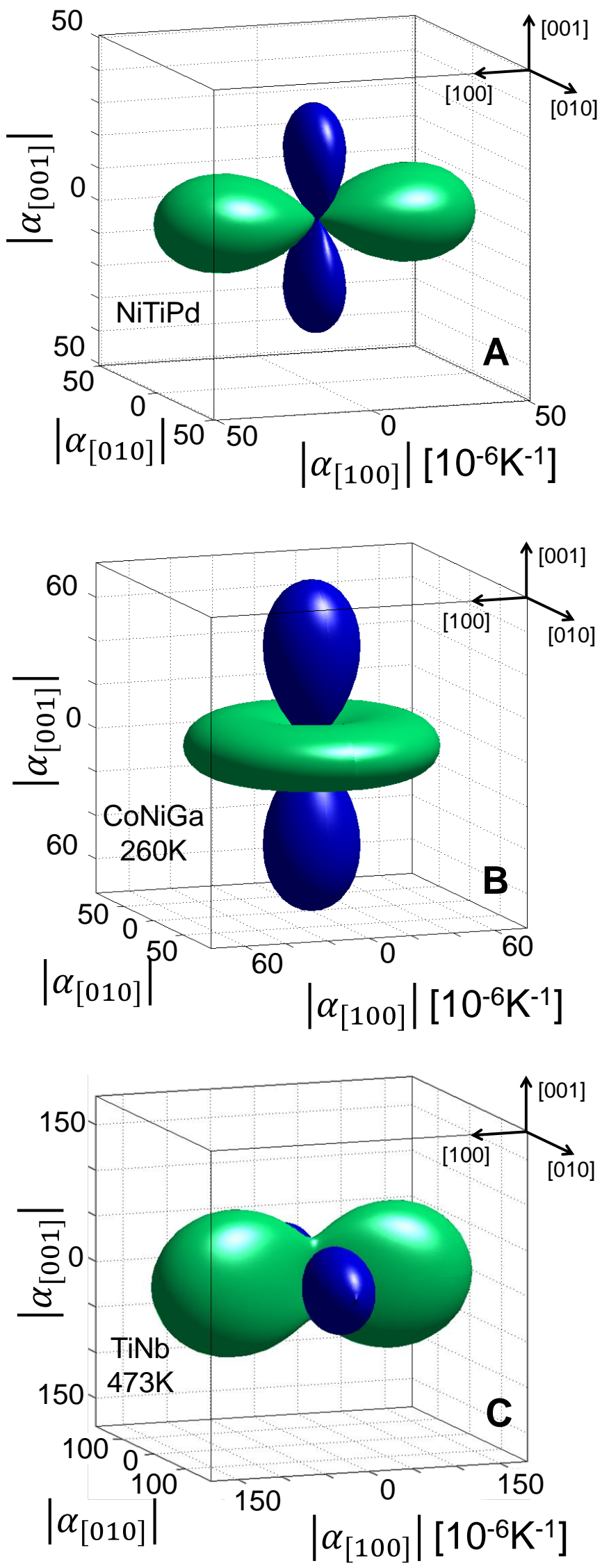
Figure 4. Graphical representation of the thermal expansion magnitudes for $\mathrm{Ni}_{19.5} \operatorname{Ti}_{50.5} \mathrm{Pd}_{30}(\mathrm{~A})$, $\mathrm{Co}_{49} \mathrm{Ni}_{21} \mathrm{Ga}_{30}$ (B), and $\mathrm{Ti}_{78} \mathrm{Nb}_{22}$ (C). Three dimensional ellipsoids showing the positive (green) and negative (blue) thermal expansion magnitudes along different crystallographic directions for orthorhombic $\mathrm{Ni}_{19.5} \mathrm{Ti}_{50.5} \mathrm{Pd}_{30}$ across all experimental temperatures shown in Figure 3, tetragonal $\mathrm{Co}_{49} \mathrm{Ni}_{21} \mathrm{Ga}_{30}$ at $260 \mathrm{~K}$ and orthorhombic $\mathrm{Ti}_{78} \mathrm{Nb}_{22}$ at $473 \mathrm{~K}$. These figures were created using Coefficient of Thermal Expansion Analysis Suite (CTEAS) software. 

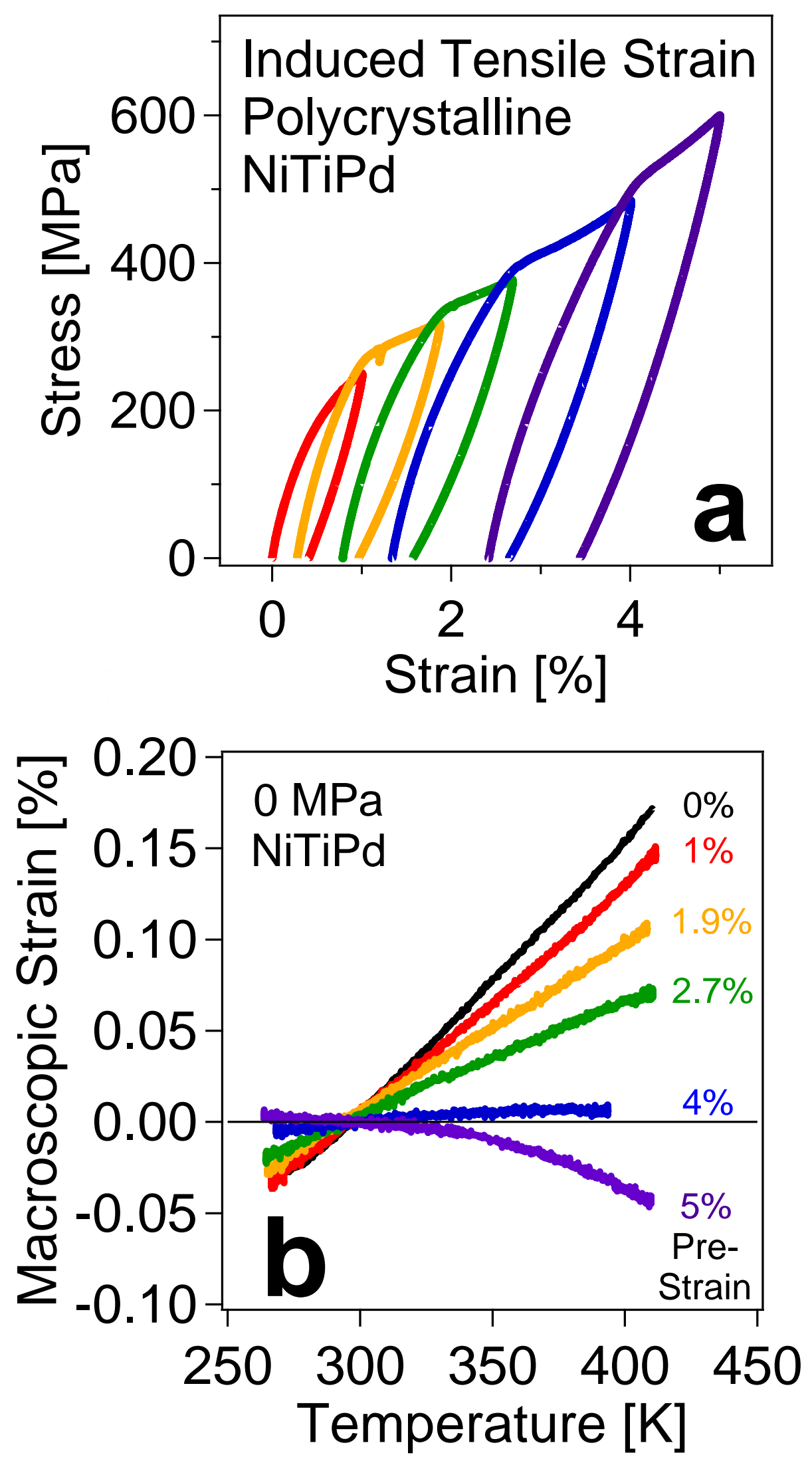


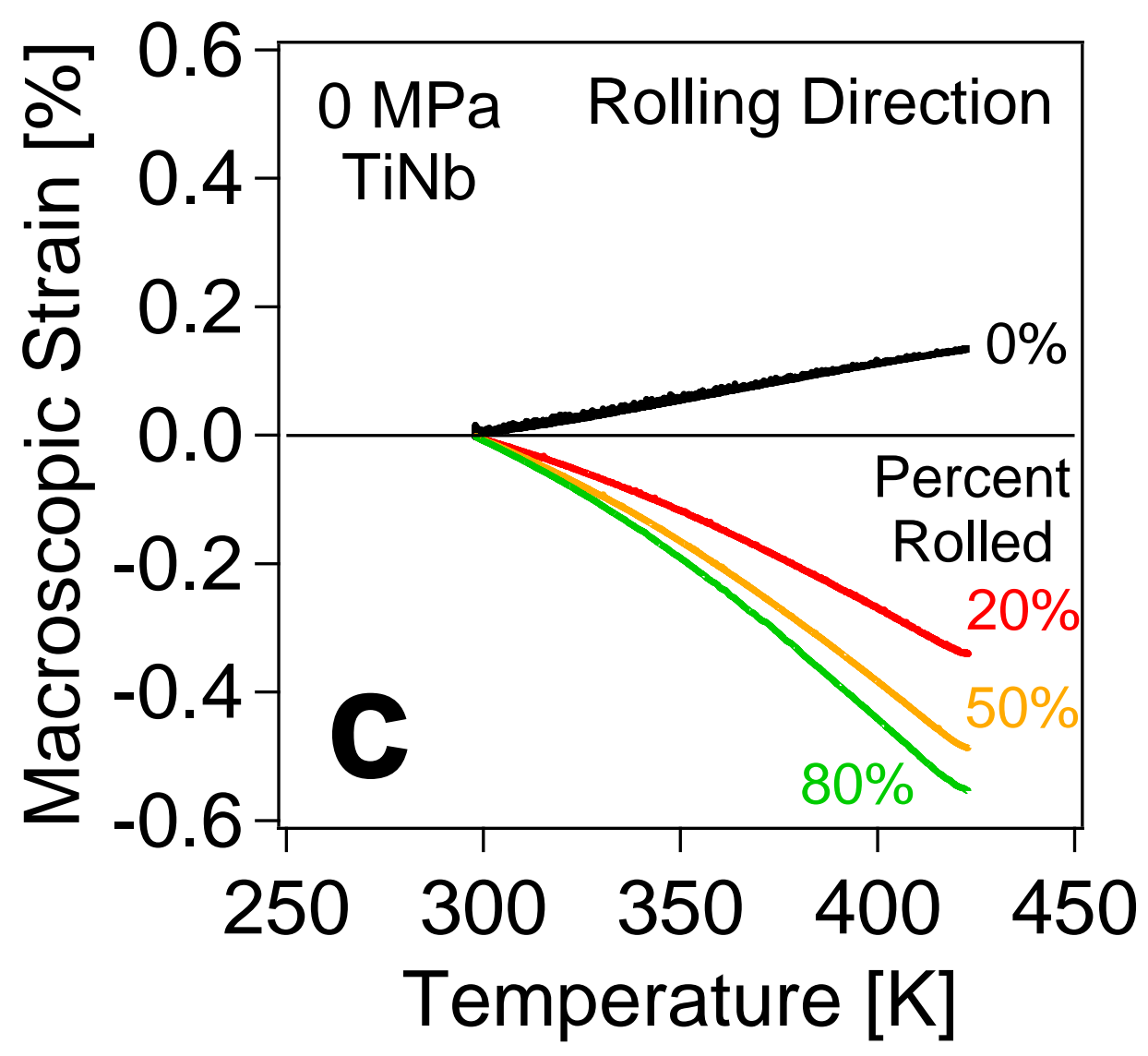

Figure 5. The incremental stress-strain response, (a), of a $\mathrm{Ni}_{19.5} \mathrm{Ti}_{50.5} \mathrm{Pd}_{30}$ polycrystal. Macroscopic strain vs temperature response of (b) tensile pre-strained $\mathrm{Ni}_{19.5} \operatorname{Ti}_{50.5} \mathrm{Pd}_{30}$ shown in (a), and (c) cold rolled $\mathrm{Ti}_{78} \mathrm{Nb}_{22}$ before and after deformation. 

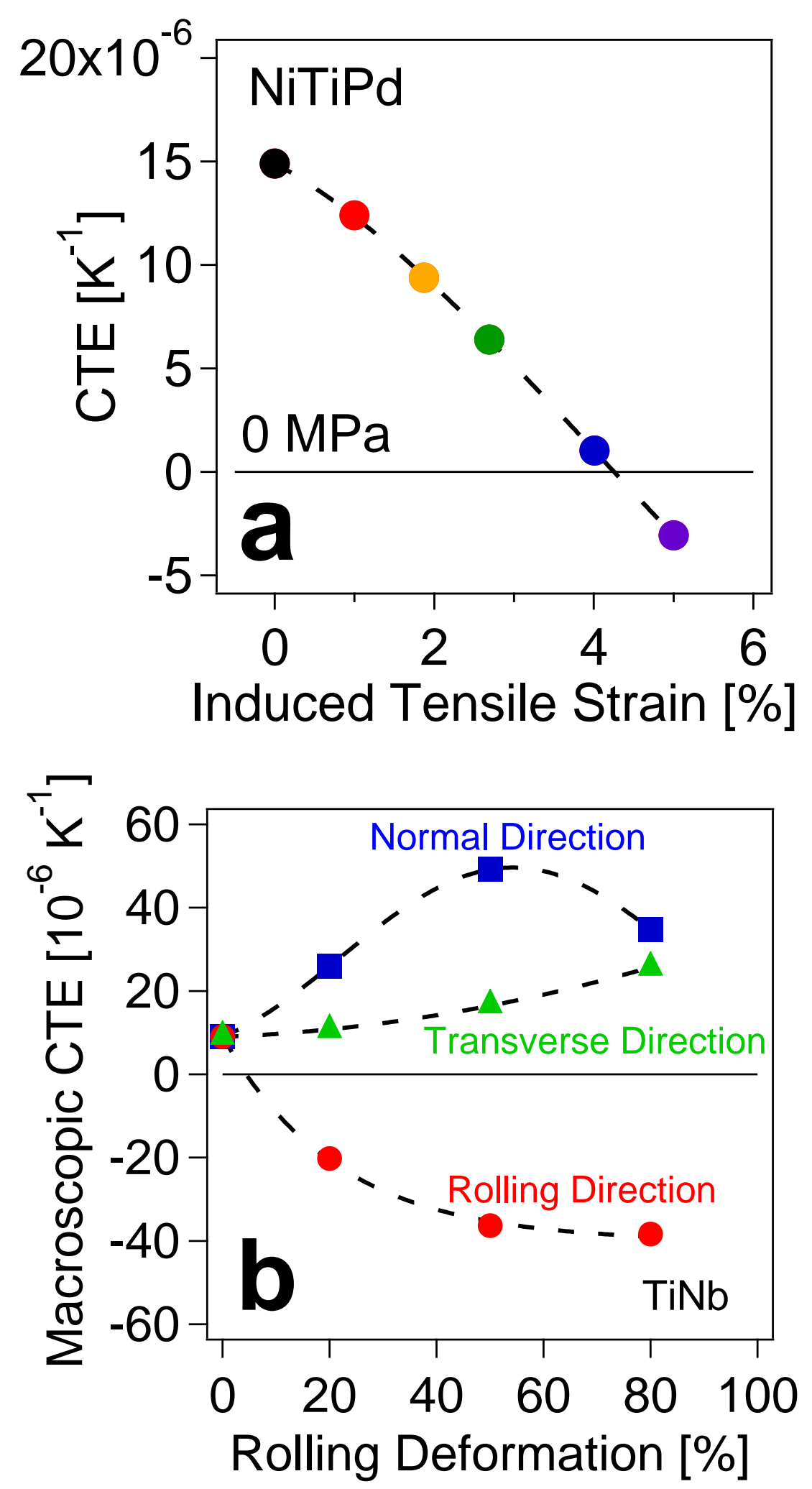

Figure 6. Macroscopic coefficients of thermal expansion vs. deformation percent for bulk

$\mathrm{Ni}_{19.5} \mathrm{Ti}_{50.5} \mathrm{Pd}_{30}$ (a) and $\mathrm{Ti}_{78} \mathrm{Nb}_{22}$ alloys (b). 


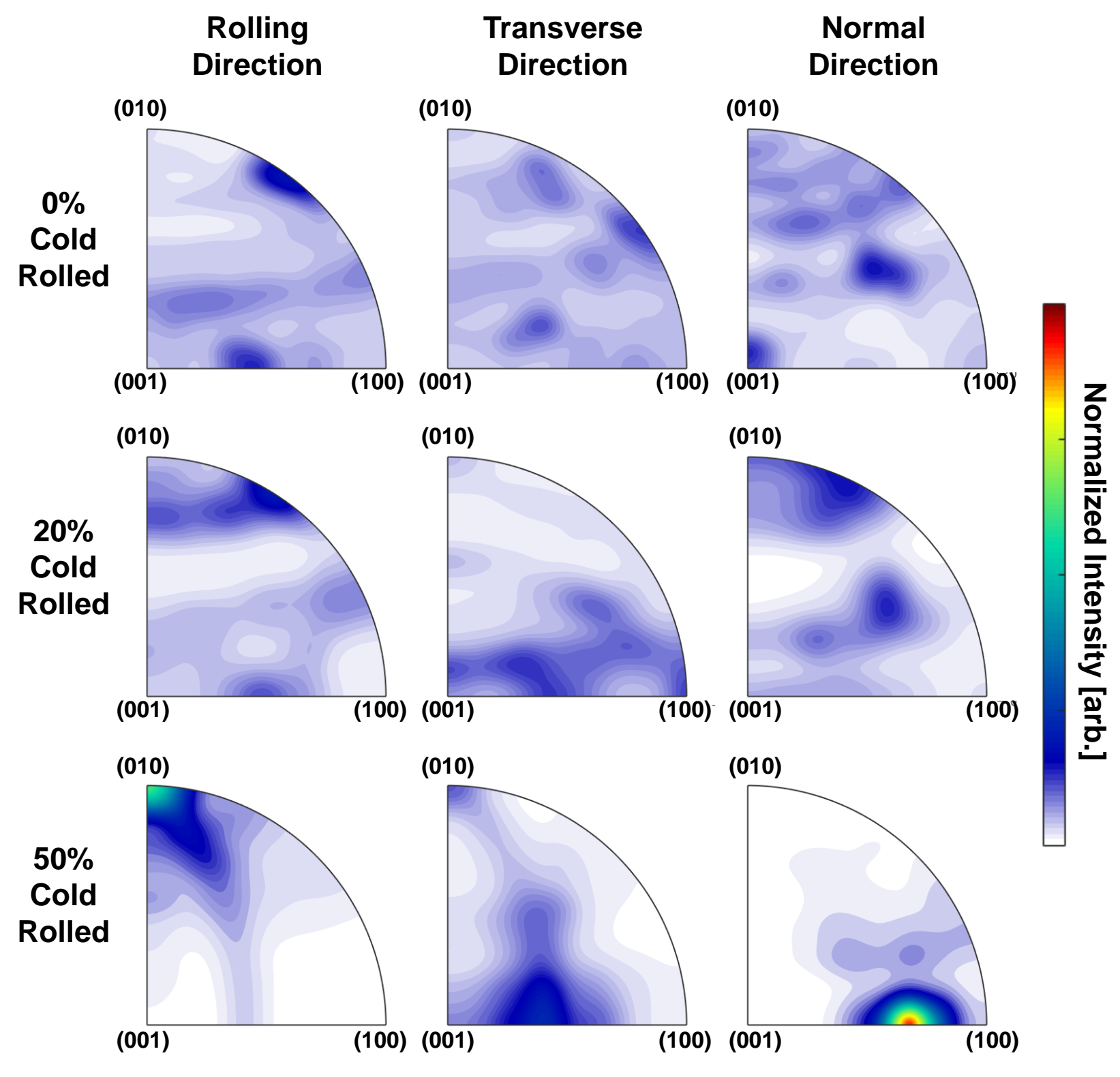

Figure 7. Inverse pole figures of as-received and rolled $\mathrm{Ti}_{78} \mathrm{Nb}_{22}$ showing the texture evolution from $0 \%, 20 \%$ and $50 \%$ cold rolling. 


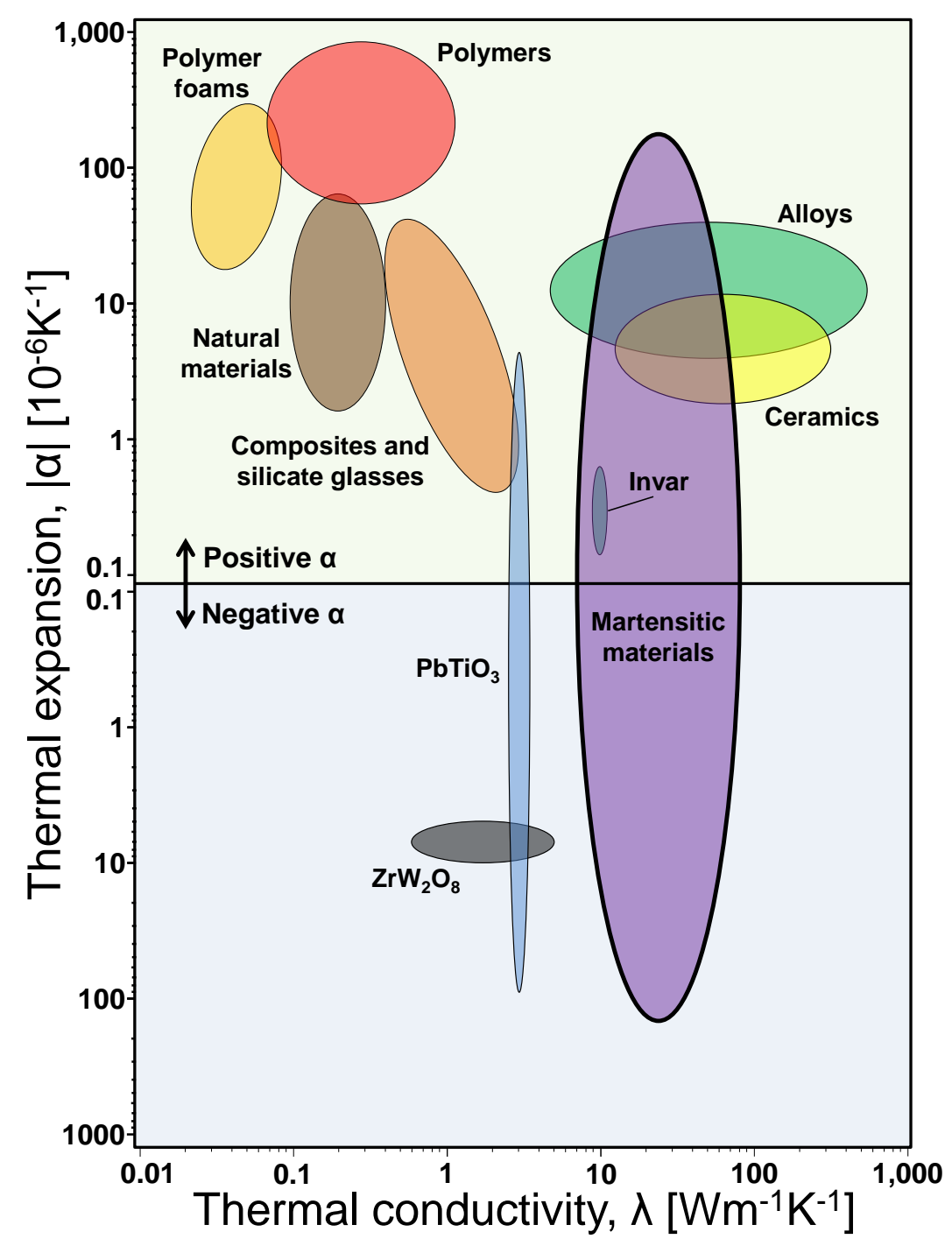

Figure 8. Thermal expansion vs. thermal conductivity for various materials. This chart compares the thermal expansion and conductivity of negative thermal expansion $\mathrm{PbTiO}_{3}, \mathrm{ZrW}_{2} \mathrm{O}_{8}$ and martensitic materials to traditional positive thermal expansion materials in the Granta Design CES materials database. 
Table 1. Thermal expansion, austenite and martensite lattice parameters, and lattice parameter comparison (See text for details) for three alloys studied in the present work and three additional materials from the literature.

\begin{tabular}{|c|c|c|c|c|}
\hline $\begin{array}{c}\text { Direction, } \\
\text { Angle }\end{array}$ & $\alpha^{M}\left(10^{-6} \frac{1}{K}\right)$ & $\begin{array}{c}\text { Austenite } \\
\boldsymbol{l}^{\boldsymbol{A}}(\AA)\end{array}$ & $\begin{array}{c}\text { Martensite } \\
l^{M}(\AA)\end{array}$ & $\begin{array}{c}R^{A \rightarrow M} l^{A}-l^{M} \\
\beta^{A}-\beta^{M}\end{array}$ \\
\hline$\overline{C \mathbf{C o}_{49} \mathbf{N i}_{21} \mathbf{G a}_{30}}$ & 4K-285K & & & \\
\hline [100] & $5.181+0.243 T$ & 5.743 & 5.422 & 2.700 \\
\hline [010] & $5.181+0.243 T$ & - & 5.422 & 2.700 \\
\hline [001] & $-5.444-0.328 T$ & - & 6.401 & -0.658 \\
\hline $\mathrm{Ni}_{19.5} \mathrm{Ti}_{50.5} \mathrm{Pd}_{30}$ & $303 K-433 K$ & & & \\
\hline [100] & 51.33 & 3.091 & 2.784 & 0.307 \\
\hline [010] & -3.17 & - & 4.450 & -0.079 \\
\hline [001] & -34.51 & - & 4.697 & -0.326 \\
\hline $\mathbf{T i}_{78} \mathrm{Nb}_{22}$ & $303 K-475 K$ & & & \\
\hline$[100]$ & $48.82+0.656 T$ & 3.305 & 3.217 & 0.088 \\
\hline [010] & $-25.94-0.579 T$ & - & 4.772 & -0.098 \\
\hline [001] & $-4.31+0.247 T$ & - & 4.652 & -0.021 \\
\hline NiTi [13] & $300 \mathrm{~K}-400 \mathrm{~K}$ & & & \\
\hline [100] & -47.2 & 3.015 & 4.67 & -0.366 \\
\hline [010] & 43.8 & - & 4.14 & 0.124 \\
\hline [001] & 22.7 & - & 2.91 & 0.105 \\
\hline$\beta$ & 29.0 & $90^{\circ}$ & $97.55^{\circ}$ & 7.550 \\
\hline Uranium [14] & $50 \mathrm{~K}-923 \mathrm{~K}$ & & & \\
\hline [100] & $24.22-9.83 \times 10^{-3} T+46.02 \times 10^{-6} T^{2}$ & 3.542 & 2.8535 & 0.689 \\
\hline [010] & $3.07+3.47 \times 10^{-3} T-38.45 \times 10^{-6} T^{2}$ & - & 5.8648 & -0.856 \\
\hline [001] & $8.72+37.04 \times 10^{-3} T+9.08 \times 10^{-6} T^{2}$ & - & 4.9543 & 0.055 \\
\hline $\mathrm{PbTiO}_{3}[10]$ & $273 K-763 K$ & & & \\
\hline$[100]$ & $\alpha_{11}=12.85+0.029 T$ & 3.958 & 3.892 & 1.705 \\
\hline [010] & $\alpha_{22}=12.85+0.029 T$ & - & 3.892 & 1.705 \\
\hline [001] & $\alpha_{33}=-24.73-0.083 T$ & - & 4.144 & -0.186 \\
\hline
\end{tabular}

The negative thermal expansion (NTE) criteria $\mathrm{l}^{\mathrm{A}}-l^{\mathrm{M}}$ and $\beta^{\mathrm{A}}-\beta^{\mathrm{M}}$ are given in $\AA$ and degrees, respectively. The high symmetry, austenite (A), and low symmetry, martensite $(\mathrm{M})$, states' lattice parameters for $\mathrm{Co}_{49} \mathrm{Ni}_{21} \mathrm{Ga}_{30}, \mathrm{Ti}_{78} \mathrm{Nb}_{22}, \mathrm{Ni}_{19.5} \mathrm{Ti}_{50.5} \mathrm{Pd}_{30}$, U [14] and $\mathrm{PbTiO}_{3}$ [10] taken $10^{\circ} \mathrm{C}$ above and below their respective martensitic transformation temperatures. The NiTi [13] martensite's lattice parameters were taken at room temperature. 
Table 2. Rotation matrices that map the austenite to the martensite basis in martensitically transforming materials.

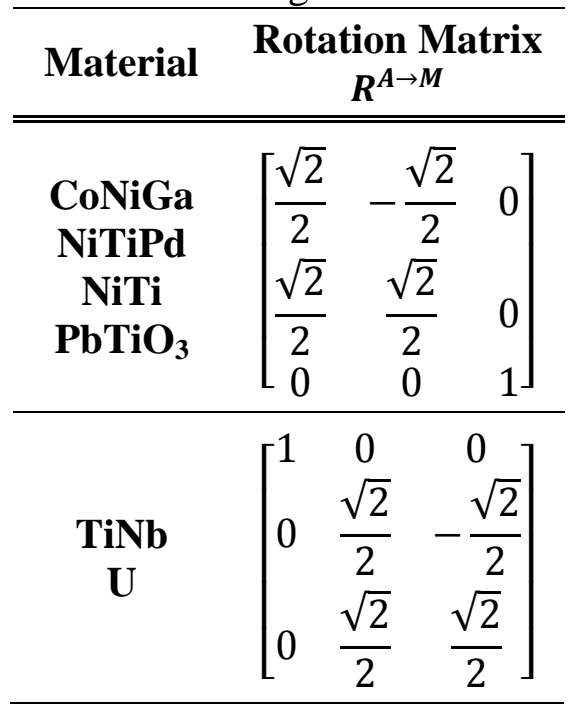




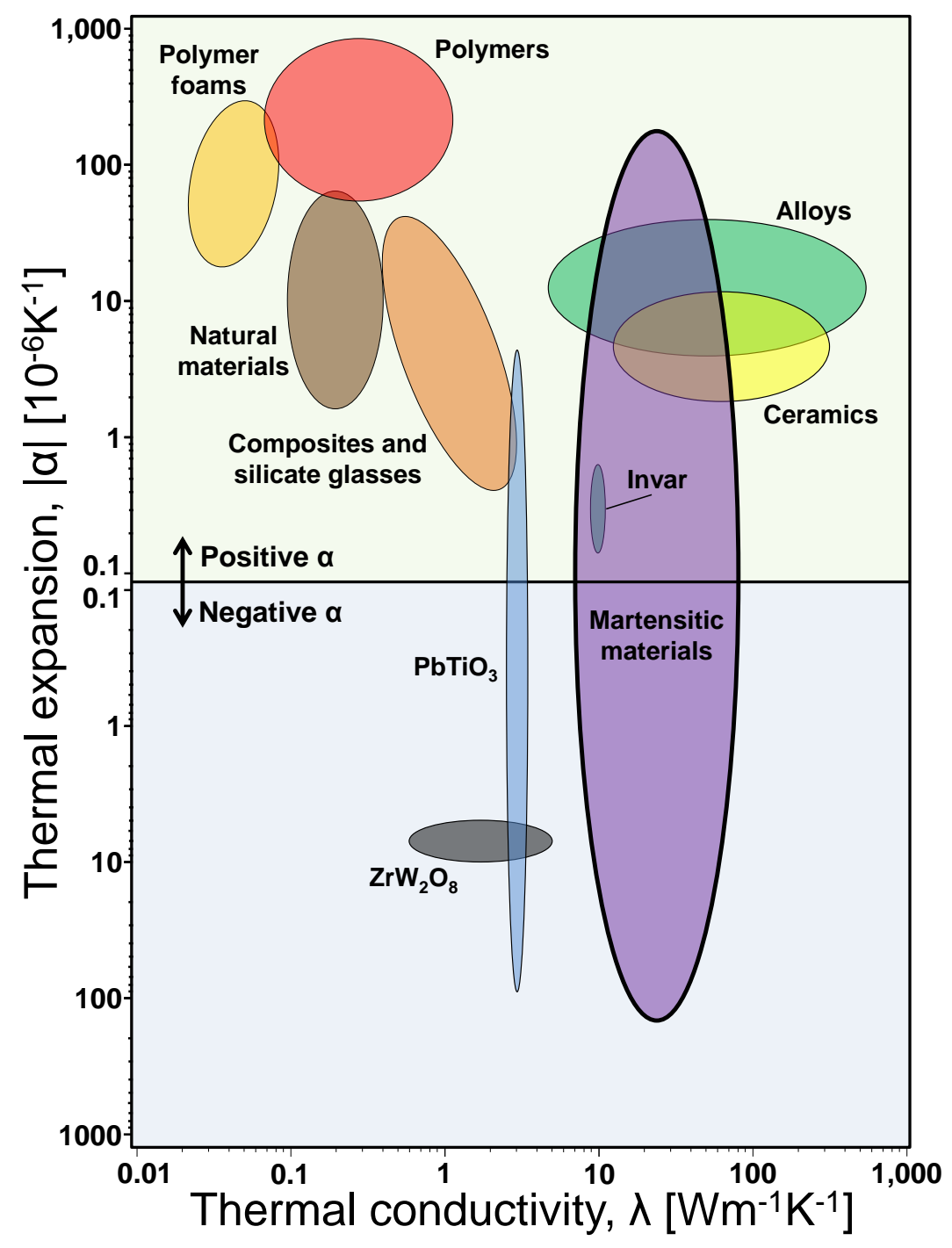

